\title{
Research on Green Design Path Based on Product Life Cycle
}

\author{
Siqi Wang, Yixuan Li, Mengtong Xie, Ruoyun Zhou, Huafeng Sun and Linxin Zheng \\ School of Design and Fashion, Zhejiang University of Science and Technology
}

\begin{abstract}
This paper aims to analyze product life cycle, introduce green design concept and integrate it into product design so as to establish feasibility path combining with China's national condition. Through case analysis, five green design principles of green co-creation, material reduction, green packaging, material replacement and design from identical material were summarized according to the five attributes of figment, product, commodity, article and waste. The whole process was analyzed with the case of indigo T-shirt. The five design principles can provide guidance for all aspects of the product, ensure the sustainability of the product, realize the optimization and upgrading of the product and achieve the goal of carbon peak and carbon neutrality.
\end{abstract}

Keywords. Green design, product life cycle, design principles, sustainability

\section{Introduction}

With the improvement of China's comprehensive national strength and social progress, people's living standards continue to improve and the understanding of the relationship between man and nature is more and more profound. At the 2020 Central Economic Work Conference, General Secretary Xi Jinping set "carbon peak and carbon neutral" as a key task for 2021 for the first time. Carbon peak refers to the annual carbon dioxide emissions of a certain region or industry reach the highest value in history, and then go through a plateau period and enter a continuous decline process. It is a historical inflection point of carbon dioxide emissions from increase to decline, marking the decoupling of carbon emissions from economic development. The peak targets include the peak year and peak value. Carbon neutrality refers to the total amount of greenhouse gas emissions directly or indirectly generated by enterprises, organizations or individuals within a certain period counteract their own carbon dioxide emissions through afforestation, energy conservation and emission reduction to achieve zero carbon dioxide emissions.

At the Leaders' Climate Summit in April 2021, Xi Jinping made a solemn promise to world leaders: "We will strive to achieve carbon peak by 2030 and carbon neutral by 2060. This is an inherent requirement for China to fulfill its responsibility to build a community with a shared future for mankind and achieve sustainable development." From the perspective of sustainable development, resource conservation and environmental friendliness, green design has gradually risen from product concept to product standard in China. Designers should focus on the dual carbon policy and establish a mechanism for harmonious development of people, society and environment through design activities, which should run through the whole life cycle of products. 


\section{Green design literature review}

In "silent spring”, U.S. Marine biologist Rachel Carson (1962) said that after the industrial era, people began to use chemical pesticides heavily, which not only bring great harm to the rivers, sea, land and plants but also damage the natural ecological balance, which greatly influenced the born of "Green Trend" in European and American countries in the last century. Victor Papanak's book "Design for the Real World" (1970) had a direct impact on the "Green Design Trend", and he first proposed the concept of design ethics. He believed that design should take seriously the limited use of the earth's resources, and design should serve to protect the limited resources of the earth we live on. According to the US Office of Technology Assessment, green design mainly refers to treating environmental factors as design opportunities or goals rather than constraints in the whole product design process. Product design should be combined with environmental problems and reduce product function, performance, service life and other losses as far as possible. Material management and waste control should be regarded as two basic objectives of product design. In China, Cao Ruixin (2004) proposed that the promotion of green design involves the whole society, which requires not only the decisions of the government and entrepreneurs but also the rationality of designers and the support of the public. The ecological values and morality of the whole people are the foundation of green design [1]. Zhang Mingyue (2012) believed that green design is rooted in people's reflection on environmental and ecological destruction, and its essence is sustainable development. It requires that the designed products have a certain promotion effect on economic society and cultural society, and do not cause damage to the ecological environment and overuse non-renewable resources [2]. Deng Yajuan (2020) emphasized that green design insists on the integration of "human-productenvironment", and the starting point and destination is ultimately to meet the needs of people [3]. In the long run, green design will be an inevitable trend of design development, which will bring new ideas and new ways to people's life, as well as new challenges and opportunities to the design industry.

\section{Green design principle and case analysis based on product life cycle}

This paper summarized the product life cycle into five steps, namely the figment, product, commodity, article and waste, corresponding to conception, manufacture, sale, use and discard. Through a large number of case studies, the researchers summarized five design principles of green co-creation, material reduction, green packaging, material replacement and design from identical material as shown in the figure.

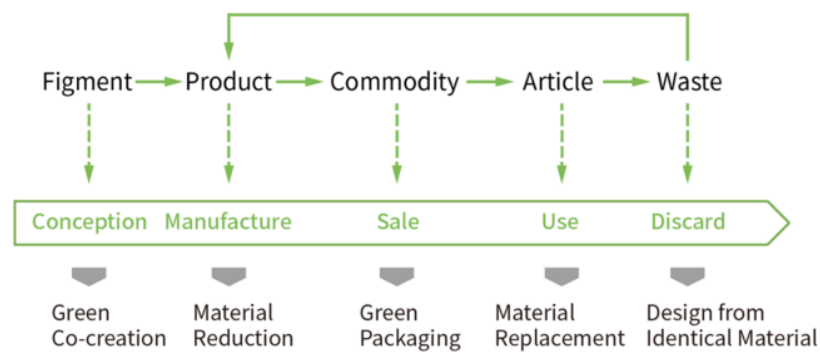

Figure 1. Five principles of green design. 


\subsection{Green co-creation}

Green co-creation refers to the integration of green design concepts in product conception. When a figment is created and conceived in the designer's mind, the designer should be responsible for the "second half of life" of the product. Also, the segment of production, sale, transportation, use and recycling of the "to be born" product should be considered overall. At the same time, designers should listen to the opinions of experts and scholars in different fields and draw on their strengths when designing so as to meet the needs of different groups of people, solve problems with systematic thinking and maximize the benefits.

Bamboo Art Studio is a representative intangible cultural heritage brand of Wuzhen Bamboo Weaving. It is committed to transforming product innovation into experience innovation, using small teaching activities to strengthen students' experience in the process of manual making, researching and developing bamboo weaving culture and creation, teaching relevant weaving skills and popularizing the "slow pace and slow enjoyment" lifestyle [4-5]. The traditional bamboo weaving is favored by modern people who advocate life aesthetics while retaining its own essence. Bamboo Art Studio cooperates with the government, handicraftsmen, villagers and tourism companies to open up resource channels and build a bamboo weaving experience system, making Chenzhuang village into a bamboo weaving art village and an intangible cultural heritage inheritance village, so that all parties can benefit from it [6-10].

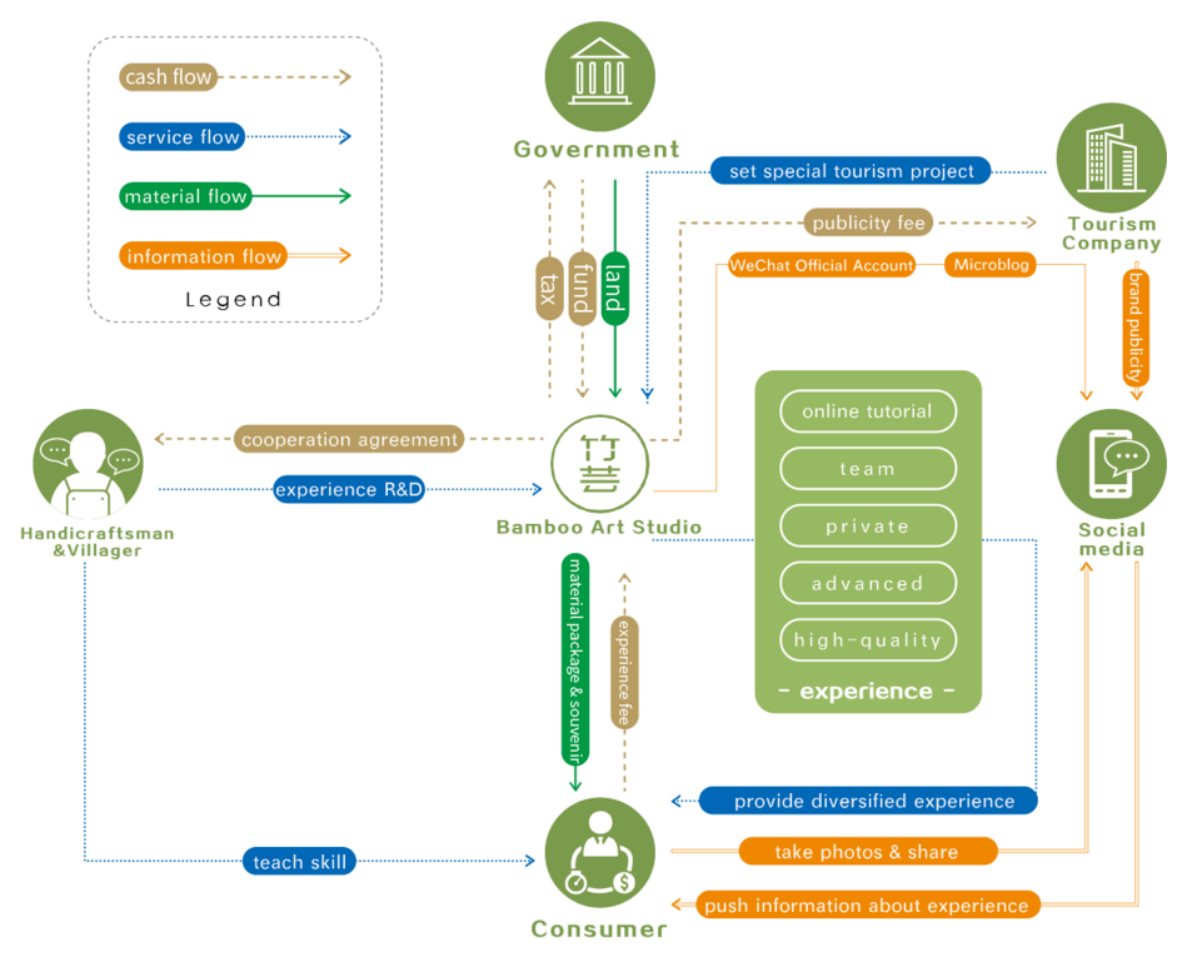

Figure 2. Bamboo art studio "Green co-creation" system map. 


\subsection{Material reduction}

Material reduction design refers to the use of materials in the production process. Designers should consider using as few materials as possible to design products that meet the needs of use. A broader definition of "dematerialization" is the absolute or relative reduction in the amount of material to fulfill its economic function. Our world is becoming more and more materialistic, consuming more resources and producing more and more waste due to the influence of bad consumption trends and population growth. In the redesign of the implementation of material reduction design, slowing down the earth's overdraft speed and reducing waste production can make our life "greener". According to this principle, designers should have an in-depth understanding of the product structure and material characteristics basing on the normal operation of the product, then extract the core structure of the product, eliminate miscellaneous decorative structure, redesign the product modeling, and design a simple and generous product image.

The tissue box in Figure 3 won the "Tokyo Midtown Award". There are 200 tissues in total, which are composed of two kinds of paper made from different materials. The first 199 tissues are as thick as the tissue we usually use. The texture of the last tissue is thicker than ordinary tissue, and it cannot be extracted because it is the tissue box itself. The tissues sold in the supermarket all have plastic or carton packaging. This piece of work not only the inside of the tissue but also the outside of the box are made of usable tissue which takes subtraction to the extreme.

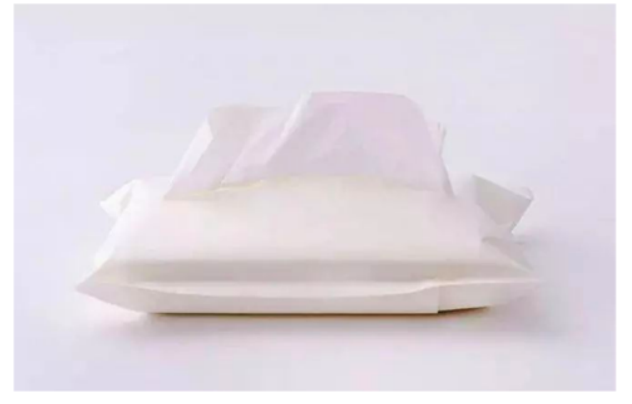

Figure 3. Award-winning tissue box.

\subsection{Green packaging}

The principle of green packaging means that the packaging used in the product sales link is green and sustainable design, which is not discarded once used, but can give full play to the function of the existing packaging from multiple angles and greatly reduce the consumption of processing and packaging waste decomposition. Through the application of innovative materials or structural components into the appropriate structure, the use value can be continued. According to this principle, designers can achieve this by optimizing structure, simplifying shape and innovating materials.

French fries are a favorite of many people. Popular fast-food brands consume a lot of potatoes every year, leaving a lot of waste potato peels behind. After analysing potato peels, Simone Caronni's team found that they were made up of starch and fibre that had the ability to bond and harden together when impregnated and dried naturally. The materials obtained by the above means are made entirely of production waste and are 
fully biodegradable. It can wrap food and then re-engage in the biological cycle as animal food or plant fertilizer when discarded.

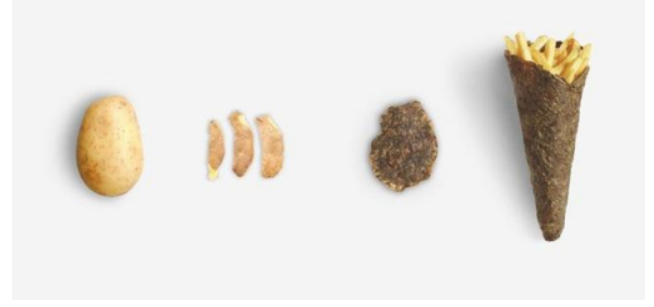

Figure 4. "Peel Saver" ecological fries packaging.

\subsection{Material replacement}

The principle of material replacement means thinking from the perspective of green design and taking consumables generated in the use of products into consideration. Also, greener and environmentally friendly energy is selected to provide energy for product.

In recent years, new energy vehicles have developed rapidly. The concept of green travel has created a growing demand for electric vehicles at home and abroad. Tesla is the leaders of new energy vehicles, which have broken the dependence of the automobile industry on internal combustion engines. Just like charging mobile phones, Tesla has designed charging piles that can be quickly charged at home. As one of the representative brands of electric vehicles, Tesla is constantly thinking and exploring in the aspect of new energy and green travel.

\subsection{Design from identical material}

This principle means on the basis of considering the recycling and treatment method of the material, the recycling and treatment process and the recycling economy, developing the possibility of material and looking for new scenes and new uses for the waste material in order to realize the efficient use of product parts, materials and energy.

The Ichi-Mai is a tote made from a single piece of laser-cut leather containing plantderived material that is flat when unfolded. Without using any tools, users can fold and assemble a three-dimensional handbag by threading several rivets through pre-punched holes. This simplifies the manufacturing process and minimizes inventory and shipping costs. Compared with traditional bags, it is more convenient to recycle.

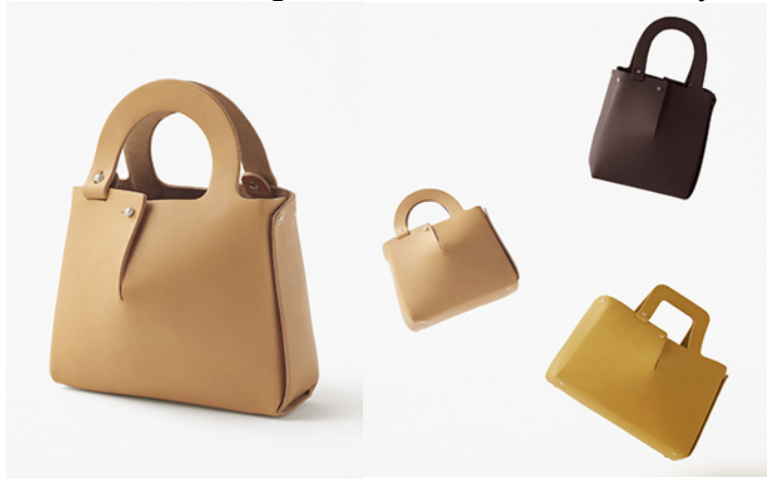

Figure 5. "Ichi-Mai" handbag. 


\section{Full life cycle design_ _ taking indigo $T$-shirt as example}

After a research trip to Qiandongnan, Guizhou Province, the team members integrated product life cycle and green design concepts into intangible cultural heritage creative design and then designed a blue dye T-shirt with Dong embroidery, as shown in the picture. Indigo T-shirt represents a more sustainable fashion philosophy aiming to combined with the traditional blue dye, the temperature of hand embroidery and different handicraft and pattern in Guizhou Province to promote more creative and delicate contracted design and give craftsman a fairer and more dignified access to income. At the same time, traditional intangible cultural heritage crafts can be activated in the market consumption.

In terms of green co-creation, the development team combined the ideas of noninheritors and modern cultural innovation thinking to realize the active inheritance of intangible cultural heritage at the very beginning. Dong people advocate freedom and believe that "everything has spirit", which is consistent with the modern concept of environmental protection. This design took biology and geometric patterns as inspiration and combined with diversified embroidery techniques, through pattern being designed, the concept of "everything has spirit" and Dong air of freedom is passed to the users. At the same time, the symbols rich in auspicious meaning such as dragon, fish, birds and butterfly were combined with Chinese characters. By integrating the understanding of these images in Han culture, the connotation of symbols can be enriched. The creation of the local embroidery craftswomen is free and random. Even if it is the work of same craftswomen, there will be subtle differences in the manual traces. This sense of handwork is also the characteristic of Dong embroidery. Therefore, in the pattern design, avoiding very neat circle, straight line and acute angle can give craftswomen certain free play space. In terms of material reduction, each T-shirt used less and fine intangible cultural heritage handicraft to shape. In terms of green packaging, the packaging of Tshirt was made of local pure natural grass and wood fiber. In terms of material replacement, each T-shirt used natural radix isatidis. There is no pesticides and chemical dye from planting to hand woven products. In terms of design from identical material, the silk thread and cloth used in each T-shirt are made of pure natural cotton and linen, and the three-dimensional effect generated by the embroidery position is made by using manual embroidery technique instead of filling and molding with chemical glue which retain the unique style of Dong handicrafts. Each T-shirt can be recycled completely after being discarded without generating additional waste materials.

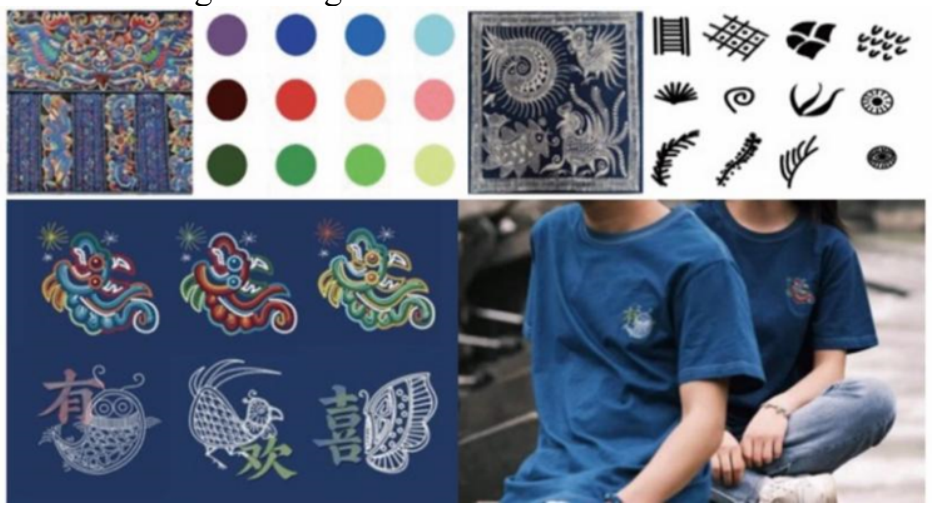

Figure 5. "Ichi-Mai" handbag. 


\section{Conclusion}

A large number of practical cases show that the five design principles can provide guidance for each link of the product, ensure the sustainability of the product, realize the optimization and upgrading of the product and achieve the goal of carbon peak and carbon neutrality. The principles proposed around green design are the needs of both the consumer market and the global natural environment. Designers need to keep the concept of green design in mind from the perspective of product life cycle and make positive contributions to sustainable development.

\section{References}

[1] R.X. Cao, "Green Design"-Design Challenge from New Era, Zhuangshi 09 (2004), 18-19.

[2] M.Y. Zhang, X.Y. Luo, Study on Convenient Yogurt Packaging Design Based on Green Design, Zhuangshi 09 (2012), 90-91.

[3] Y.J. Deng, The Thinking of Interior Furniture Design Based on Green Design Concept, Packaging Engineering 12 (2020), 325-329.

[4] L.X. Zheng, S.Q. Wang, Design of Bamboo Weaving Experience Based on User Experience Map, Packaging Engineering 14 (2020), 154-159.

[5] H.P. Wang, L.X. Zheng, Traditional Handicraft Redesign Under the Background of Media Mergence, Packaging Engineering 08 (2019), 261-265.

[6] C.L. Deng, Touchpoints of Touch Service, Zhuangshi 06 (2010), 13-17.

[7] N. Wang, Study on Rural Service Design for All-for-one Tourism: Taking Song'ao Town in Ningbo as an Example, Zhuangshi 05 (2017), 142-143.

[8] Y.M. Wang, W.F. Hu, Travel Postcard Service Design Based on User Experience Trip, Packaging Engineering 22 (2016), 158-163.

[9] S.J. Luo, S.S. Zhu, Service Design, Machinery Industry Press, Beijing, 2011.

[10] Y.X. Lu, S.Q. Sun, K.J. Zhang, Research on Development Strategy of Innovation Design, Journal of Machine Design, 02 (2019), 1-4. 